\title{
DIE ROL VAN DIE APTEKER IN DIE FARMASEUTIESE INDUSTRIE*
}

Om 'n indruk te kan vorm van die omvang van die SuidAfrikaanse Farmaseutiese Industrie en die rol wat die apteker hierin speel, is dit nodig dat die ontwikkeling van hierdie industrie in die Republiek van Suid-Afrika kortliks geskets word.

Voor die Tweede Wêreldoorlog was die plaaslike farmaseutiese produksie klein in vergelyking met die hoeveelheid klaar vervaardigde, ingevoerde goedere. Daar was ongeveer tien vervaardigingslaboratoria wat die soorte medisyne vervaardig het wat algemeen in gebruik was, en wat die voorafgaande 10 tot 20 jaar weinig verander het.

Soos die oorlog ontwikkel het is invoere uit Europa gestaak en het die V.S.A. die hoofverskaffer van medisyne geword; steeds in die vorm van verpakte geneesmiddels, gereed vir gebruik.

Die Farmaseutiese Industrie, soos dit destyds was, was nie in 'n posisie om voordeel te trek uit die situasie, angesien dit nie beskik het oor die apparaat, kennis of grondstowwe nie.

Kort voor die uitbreek van die Tweede Wêreldoorlog, is ' $n$ belangrike deurbraak gemaak in die ontwikkeling van sintetiese organiese verbindings vir die behandeling van spesifieke siektes. Verbindings soos M \& B 693 het daartoe gelei dat daar feitlik ' $n$ revolusie in farmaseutiese vervaardigingstegnieke gevolg het.

Die daaropvolgende ontwikkeling van nuwe geneesmiddels, soos die antibiotikum penisillien, die breë-spektrum antibiotika chlooramfenikol en die tetrasikliene, die steroiede ens., het nuwe eise aan die vervaardiging van verskillende doseringsvorme gestel.

Bogenoemde ontwikkeling asook die groter mate van patentbeskerming, het oorsese maatskappye tot plaaslike vervaardiging van hul produkte gestimuleer. Hierdie maatskappye, wat in die meeste gevalle filiaalmaatskappye was van die grootste Amerikaanse, Britse en Switserse firmas, het nuwe skoling gebring: skoling in vervaardiging, bestuur, administrasie en

\footnotetext{
* Intreerede gelewer by die aanvaarding van 'n professoraat in Farmaseutika aan die P.U. vir C.H.O., op 3 Mei 1968, deur prof. dr. M. C. B. v. R. van Oudtshoorn.
} 
verkoopstegnieke, wat oorgedra is aan Suid-Afrikaners, wat die grootste persentasie van die personeel van hierdie firmas uitgemaak het.

In 1958 was daar reeds 51 farmaseutiese laboratoria met ongeveer 3000 persone in diens, en met 'n produksie van ongeveer R10 miljoen.

Dit word in die algemeen nie besef dat alle farmaseutiese vervaardiging uitgevoer word onder wette soos dit op geen ander industrie van toepassing is nie. Alle vervaardiging moet onder voortdurende toesig van aptekers uitgevoer word. Baie geneesmiddels is vergifte en gewoontevormend, en buitengewone voorsorgmaatreëls moet by die hantering daarvan getref word. Daarbenewens moet kwaliteitskontrole van die grondstof af tot die eindproduk uitgeoefen word. Al hierdie faktore bring mee dat hierdie industrie van 'n hoër persentasie professioneel gekwalifiseerde personeel as meeste ander industrieë gebruik maak.

Soos vandag nog, is die ontwikkeling van die farmaseutiese industrie in die verlede grootliks gestrem deur 'n gebrek aan 'n sterk sekondêre chemiese industrie. 'n Groot persentasie van die moderne geneesmiddels is komplekse organiese verbindings waarvan die individuele dosisse in die verskillende doseringsvorme in milligram-hoeveelhede uitgedruk word. Hierdie relatief klein hoeveelhede chemikalieë wat in die meeste gevalle baie duur is, moet vervaardig word deur 'n gespesialiseerde chemiese vervaardiger, wat weer op sy beurt deur 'n hoogsontwikkelde basiese chemiese industrie gesteun moet word. ' $n$ Begin is egter gemaak deur die oprigting van Sasol en ander ondernemings, wat reeds op 'n beperkte skaal sekere basiese grondstowwe kan lewer vir die vervaardiging van fyn chemikalieë wat nodig is vir die farmaseutiese industrie. Indien hierdie skakel in die toekoms uitgebrei kan word, behoort SuidAfrika selfonderhoudend te wees wat bestaande geneesmiddels betref. Ons het tans ' $n$ farmaseutiese industrie wat, indien dit die verfynde grondstof kan bekom, oor genoegsame middele beskik om alle geneesmiddels te vervaardig, wat sal voldoen aan die land se behoeftes, met 'n bepaalde grens vir uitvoer.

Die verskillende vertakkings van die farmaseutiese bedryf, wat deel het in die invoer, vervaardiging, hantering en verkoop van medisyne is die volgende:

1. Plaaslike takke van groot internasionale farmaseutiese maat- 
skappye, wat ook die sterkste groep is. Die maatskappye bemark hoofsaaklik medisyne wat patentbeskerming geniet.

2. Plaaslike firmas, wat agentskappe van buitelandse maatskappye hou en ook hul eie preparate op 'n beperkte skaal vervaardig. Gepatenteerde, asook produkte waarvan die patente reeds verval het, word vervaardig en bemark.

3. Die kleiner plaaslike vervaardiger wat medisyne uit ingevoerde grondstowwe vervaardig. Die vervaardigde produkte is hoofsaaklik dié waarvan patente reeds verval het.

4. Die groothandel, wat op groothandelvlak die verspreiding vir die eerste drie groepe behartig.

5. Die kleinhandelapteker wat medisyne aan die publiek voorsien.

Dit is belangrik om daarop te wys dat ten spyte van 'n relatiewe klein mark daar nagenoeg 120 firmas is wat onder die eerste drie kategorieë val en op die meeste vlakke met mekaar kompeteer. Verder word hierdie klein mark feitlik uitsluitlik deur die blanke ekonomie gedra, aangesien die inkomste van die nie-blanke groep sodanig is dat dit nie die koste van duur medisyne kan dra nie, en dus gratis mediese behandeling van hospitale en distriksgeneeshere ontvang. Soos in die verslag van die Snyman-kommissie oor die koste van mediese dienste aangedui is, maak dit 'n baie belangrike gedeelte van die staatsuitgawe uit. Van die totale produksie van sogenaamde etiese geneesmiddels in die land word tans ongeveer $25 \%$ deur die sentrale regering en die verskillende provinsiale administrasies aangekoop. In 1966 was die medisyneaankope van die Transvaalse Provinsiale Administrasie ongeveer R6 miljoen, wat bykans die helfte van die totale aankope van bogenoemde sektor verteenwoordig.

Die totale waarde van gedistribueerde geneesmiddels wat deur genoemde vyf groepe hanteer is, is soos volg:

$\begin{array}{cccccc}1962 & 1963 & 1964 & 1965 & 1966 & 1967 \\ \text { R25m } & \text { R29m } & \text { R35m } & \text { R40m } & \text { R45m } & \text { R51m }\end{array}$

Volgens gegewens deur die Raad van Handel en Nywerheid verskaf, verteenwoordig die aandeel van die kleinhandelapteker slegs $23 \%$ van die totale distribusie. Dit gee die situasie egter nie heeltemal korrek weer nie, aangesien die $50 \%$ deel van die groothandel ook gedeeltelik deur die kleinhandel herdistribueer word. 
Sover dit die wêreldhandel van farmaseutiese produkte betref, het Suid-Afrika reeds in 1964 onder die 12 lande getel wat $2 \%$ en meer van die uitvoermark van ongeveer $\mathrm{k} 1,000$ miljoen gehad het. Die internasionale handel in farmaseutiese preparate verskil daarin van die plaaslike mark dat dit geweldig prysgevoelig is vir alle geneesmiddels wat nie van die nuutste en mees ontwikkelde op 'n bepaalde gebied is nie.

Aangesien daar in Suid-Afrika geen oorspronklike navorsing gedoen word wat produkte kan lewer om vir laasgenoemde groep te kwalifiseer nie, word die uitvoermark dus hoofsaaklik betree met plaaslik vervaardigde produkte waarvan patentbeskerming reeds verval het. Die feit dat ons op hierdie gebied mededingend kan wees, kan hoofsaaklik toegeskryf word aan die hoë ontwikkelingspeil wat op die gebied van industriële farmasie in ' $n$ betreklike kort tyd bereik is. Indien Suid-Afrika ooit die posisie wil bereik waar daar navorsing gedoen kan word vir die ontwikkeling van geneesmiddels wat patentbeskerming kan geniet, is dit noodsaaklik dat die uitvoermark sover as moontlik benut word. Slegs firmas wat op 'n deel van die internasionale mark kan staatmaak kan dit uiteindelik bekostig om oorspronklike navorsing te doen.

Dit word bereken dat ' $n$ farmaseutiese maatskappy wat homself in oorspronklike navorsing wil begewe en van 'n redelike mate van sukses verseker wil wees, in die omgewing van R2 miljoen per jaar aan navorsing moet bestee. Om 'n navorsingskapasiteit in ' $n$ beperkte veld op te bou, soos wat die ervaring mag aandui, is die minimum koste nogtans in die omgewing van $\mathrm{R} 400,000$ per jaar. Om hierdie rede neig farmaseutiese firmas om groter te word deur samesmelting van kleiner maatskappye, en terselfdertyd het die industrie internasionaal geword. In Suid-Afrika is ongeveer 80 internasionale maatskappye aktief besig om hul produkte te bemark, hetsy deur filiaalmaatskappye of deur agentskappe.

Daar bestaan sover aan my bekend in Suid-Afrika geen farmaseutiese maatskappy wat, indien dit $10-50 \%$ van sy netto wins aan navorsing sou spandeer, in staat sou wees om bogenoemde bedrag te bereik nie. Om nie eers die aanvanklike kapitale uitleg aan geboue en apparaat te noem nie.

Die enigste uitweg wat gevolg kan word om uiteindelik 'n selfstandige posisie te bereik, is om 'n sterk industrie op te bou, al is dit deur produkte te vervaardig waarvan die 
patentbeskerming verval het, maar nogtans algemeen in ge bruik is. Dit is nie korrek om firmas wat sulke produkte vervaardig en verkoop as rowerfirmas te bestempel, soos dikwels hier te lande gedoen word nie. Suid-Afrikaanse firmas het nog altyd patente erken en daar was nog geen bewys van patentdiefstal nie; iets wat nie altyd van alle lande gesê kan word nie. In sulke gevalle kan alleen van rowerfirmas gepraat word.

Wat wel belangrik is, is dat indien sulke produkte vervaardig en verkoop word, daar sorg gedra moet word dat dit in alle opsigte ekwivalent is aan die oorspronklike produk, en ook dieselfde kliniese effektiwiteit moet waarborg.

Daar bestaan dus genoeg ruimte vir nie soseer navorsing nie maar vir die ontwikkeling van bestaande doseringsvorme of nuwe doseringsvorme. Op hierdie wyse kan teen 'n relatiewe lae koste 'n kundigheid opgebou word wat in toekomstige jare kan lei tot oorspronklike navorsing en die totstandkoming van 'n eie omvattende Suid-Afrikaanse Farmaseutiese Industrie.

Die verskillende geneesmiddel-doseringsvorme wat algemeen in gebruik is, kan vir produksiedoeleindes in verskillende groepe ingedeel word. Die indeling geskied hoofsaaklik op grond van die tipe materiaal wat gebruik word, asook die produksiemetode wat gevolg word. Die doseringsvorme is die volgende:

1. Vaste doseringsvorme

1964

1.1 Tablette

1.2 Harde gelatien kapsules

1.3 Pille

1.4 Poeiers vir inwendige gebruik

1.5 Poeiers vir uitwendige gebruik

totaal $\mathbf{R 9 , 7 9 2 , 5 0 0}$

2. Vloeibare doseringsvorme

2.1 Oplossings

2.2 Emulsies

2.3 Suspensies

2.3 Suspensies

2.4 Neus- en ander druppels

$\mathrm{R} 4,872,100$

3. Steriele doseringsvorme

3.1 Ampulle- en enkeldosishouers

3.2 Meervoudige dosishouers

3.3 Infuusvloeistowwe

3.4 Oogdruppels en oogsalwe

3.5 Vaksiene en sera

$\mathbf{R 3}, \mathbf{7 4 1 , 7 0 0}$ 
4. Halfvaste en plastiese doseringsvorme

4.1 Sagte gelatien kapsules

4.2 Salwe

4.3 Setpille

$\mathrm{R} 1,027,000$

5. Aërosolpreparate

R 35,200

6. Hollandse medisyne

R 36,300

Die vaste doseringsvorme is vandag verreweg die belangrikste. Soos uit bogenoemde syfers gesien kan word, maak tablette die belangrikste deel van hierdie groep uit.

Dit is vanselfsprekend dat die belangrikheid van hierdie doseringsvorm toegeskryf kan word aan die gemak waarmee dit ingeneem kan word, en verder dat dit goedkoop is aangesien dit in groot massas vervaardig kan word.

Wanneer die statistiek met betrekking tot die verskillende doseringsvorme vergelyk word met die van ander lande wat bekend is, is daar onmiddellik twee opvallende verskille, naamlik die groot verbruik aan poeiers vir inwendige gebruik asook die gebruik van die sogenaamde Hollandse medisyne in SuidAfrika. Die verbruik van laasgenoemde groep het egter die afgelope aantal jare feitlik dieselfde gebly, alhoewel die gewildheid (van hierdie groep) geensins afgeneem het nie.

Daar het in die farmaseutiese industrie gedurende die afgelope 15 jaar 'n geweldige ommeswaai ten opsigte van produksiemetodes gekom. Dit stel nuwe eise aan die industrieapteker wat hierdie produksie moet beheer en behartig.

Waar farmaseutiese formulering en produksie 30 jaar gelede as ' $n$ kuns beskou is, moet die moderne apteker dit wetenskaplik kan aanpak en ook gebruik maak van wetenskaplike hulpmiddels om te verseker dat hy steeds die beste en mees effektiewe produk vervaardig.

Die wetenskap wat die grootskaalse vervaardiging van verskillende doseringsvorme afbaken, staan in Europese lande bekend as Galeniese Farmasie of kortweg Galenika. In die Engelssprekende wêreld kom daar verskillende benaminge voor waaronder Technical Pharmacy, Pharmaceutical Technology en Industrial Pharmacy. Ek glo dat die korrekte Afrikaanse benaming Industriële Farmasie sou wees, in teenstelling met Farmaseutiese Tegnologie.

Ten einde met vrug op hierdie gebied te kan werk, is dit 
noodsaaklik om goed onderlê te wees in verskillende dissiplines, waaronder farmaseutiese chemie, fisiese chemie, organiese chemie, farmakologie, mikrobiologie en wiskunde.

Aangesien dit in Suid-Afrika deur die Wet op Geneeshere, Tandartse en Aptekers vereis word dat alle vervaardiging van medisyne onder voortdurende toesig van 'n apteker moet wees, is dit noodsaaklik dat hy oor 'n sekere kennis van die ekonomiese wetenskappe moet beskik. Dit is onbegryplik dat 'n persoon wat aan die hoof van 'n onderneming met ' $n$ omset van miljoene rande staan, dit na behore op 'n sakegrondslag kan administreer indien hy nie oor so ' $n$ bepaalde agtergrond beskik nie. Dieselfde geld ook van die kleinhandelapteker wat immers ook 'n deel uitmaak van die groter Farmaseutiese Industrie.

$\mathrm{Na}$ aanleiding van resultate wat die afgelope sewe jaar gepubliseer is, wil ons kortliks enkele faktore noem wat in ag geneem moet word by die formulering van bepaalde doseringsvorme, en volstaan met die wat vir orale gebruik bestem is

Die hoofgroepe kan vir hierdie doeleindes ingedeel word in 'n volgorde wat die beskikbaarstelling van aktiewe bestanddele verteenwoordig. Waterige oplossings $>$ suspensies $>$ poeiers $>$ kapsules $>$ tablette $>$ bedekte tablette.

Met verwysing na die volgorde word aangeneem dat die aktiewe geneesmiddel stabiel is in die vloeistowwe van die spysverteringskanaal. Die omgekeerde van die volgorde kan voorkom wanneer dit onstabiel is in die maagsappe. Verder is die volgorde gebaseer op die gewone eienskappe van groepe en uitsonderings kan dus voorkom. Emulsies, preparate met verlengde of onderhoudende werking, aërosole en setpille word nie ingesluit nie, aangesien dit ingewikkelder sisteme verteenwoordig en afsonderlik beoordeel sal moet word.

Geneesmiddels word vinniger geabsorbeer uit die spysverteringskanaal wanneer dit in waterige oplossings ingeneem word. Beperkende faktore soos oplosbaarheid, swak stabiliteit, slegte smaak en ekonomiese vereistes mag die gebruik van 'n ander doseringsvorm nodig maak. In die afwesigheid van sulke faktore is ' $n$ waterige oplossing egter die mees ideale doseringsvorm wanneer ' $n$ vinnige en betroubare absorpsie nodig is. Dit word ook maklik ingeneem en voorkeur word daaraan gegee in die pedriatiese en geriatriese geneeskunde.

Suspensie is 'n effektiewe doseringsvorm wat volg op op- 
lossings, omdat dit 'n EToot oppervlak van die gedispergeerde vaste stof blootstel. Deeltjie-grootte is 'n kritiese faktor, aangesien vinniger dissolusie en absorpsie verkry kan word deur gebruik te maak van kleiner poeierdeeltjies. Verskeie faktore kan veroorsaak dat 'n goeie suspensie uiteindelik verander in 'n totaal onaktiewe produk. Een so 'n faktor is byvoorbeeld die voorkoms van polomorfisme. Daar word meestal gebruik gemaak van die metastabiele vorm, aangesien dit die aktiewe vorm is wanneer daar ' $n$ verskil in werking bestaan. Hierdie vorm sal egter geleidelik oorgaan in die termodinamies meer stabiele vorm en dus sodoende 'n onaktiewe produk vorm. Deur gebruik te maak van bepaalde hulpstowwe, byvoorbeeld dié ter verhoging van viskositeit, kan die probleem oorbrug word.

'n Ander faktor wat in ag geneem moet word is die adsorpsie van die aktiewe bestanddeel aan hulpstowwe of ander aktiewe bestanddele. Soos byvoorbeeld die adsorpsie van atropien aan kaolien in kaolien- en pektien-suspensies.

Faktore wat die biologiese beskikbaarheid van poeiers kan beinnloed is betreklik maklik identifiseerbaar; dit is gewoonlik deeltjie-grootte, polimorfisme, dissolusie-snelheid en moontlike interaksie met hulpstowwe of ander aktiewe bestanddele.

In 'n onlangse ondersoek is nagegaan tot watter mate die doseringsvorm die relatiewe biologiese beskikbaarheid van spironolaktoon kan beïnvloed. By toediening van die verbinding in die vorm van 'n los geenkapsuleerde poeier en kommersieël beskikbare tablette is gevind dat die poeier in kapsules $6.6 \mathrm{keer}$ beter geabsorbeer word as die tablette. By die toediening van gemikroniseerde spironolaktoon was die absorpsie 10 keer hoër as vir die tablette. Mikronisering het dus die absorpsie uit die spysverteringskanaal sodanig verhoog dat $40 \mathrm{mg}$. dieselfde bloedspieël-tydwaardes gee as $400 \mathrm{mg}$ in die vorm van konvensionele tablette.

Saamgeperste tablette, wat die mees gebruikte doseringsvorm is, bied ook sommige van die moeilikste probleme met betrekking tot die biologiese beskikbaarheid van die aktiewe bestanddele.

In 'n kommentaar op die invloed van tableteienskappe op die absorpsiesnelheid van Penisillien $V$ het Juncker en Raaschou die volgende opmerking gemaak: „many published studies that do not describe the pharmaceutical properties of the preparations used can hardly be considered indicative of an estimate 
of the absorption of the penicillin compounds concerned". Die outeurs voer dit ook as argument aan vir die baie teenstrydige resultate en gevolgtrekkings ten opsigte van die orale gebruik van penisillien.

Desintegrasietyd beinvloed die absorpsie van die geneesmiddel deur die oplossingsproses te bevorder. Fragmentasie van die tablet verhoog die oppervlak en versnel die oplossingsnelheid. Desnieteenstaande is die desintegrasietyd 'n swak indeks van die beskikbaarheid van 'n geneesmiddel.

In 'n ideale geval sou tablette en ander doseringsvorme beoordeel moet word deur 'n oplossingsnelheidtoets; maar selfs die beste in vitro-toets sal nogtans nie in alle gevalle die in vitro-gedrag voorspel nie.

Bedekte en enteries bedekte tablette bied bepaalde probleme wat hoofsaaklik toe te skryf is aan die metode van vervaardiging. Met die gebruik van outomatiese bedekkingsmasjiene, veral die wat bestem is vir filmbedekking, kan die probleem oorbrug word. Die gebruikmaking van sintetiese polimere as filmvormers verseker dat gelykmatige resultate verkry word.

Grootskaalse produksie en verpakking van doseringsvorme vereis dat die verskillende eenheidsprosesse, soos in die industrie van toepassing is, behoorlik verstaan en beheer moet word.

Die gebruik van hoëspoed-tabletmasjiene, wat in staat is om 1 miljoen tablette per dag te maak, kontinue prosesse vir die vervaardiging van inspuitings, maak dit noodsaaklik dat kwaliteitskontrole strenger toegepas moet word. Dit is nie alleen belangrik dat laboratoriumkontrole meer aandag moet geniet nie, maar ook kontrole tydens die hele vervaardigings- en verpakkingsproses.

\section{BIBLIOGRAFIE:}

1. Cooper, M. H.: Prices and Profits in the Pharmaceutical Industry; Pergamon Press, London 1966.

2. Friend, D. G.: Clin. Pharm. \& Therap. 3, 417-420 (1962).

3. Levy, G.: Prescription Pharmacy; Ed. J. B. Sprowls; J. B. Lippincott and Company, Philadelphia, 1963.

4. Munzel, K.: Progress in Drug Research 10, 204-359 (1966).

5. Nelson, E.: Clin. Pharm. \& Therap. 3, 673-681 (1962)

6. Republic of South Africa: Board of Trade and Industries; Industrial Development Series Number 2 and 5. 